\title{
Em defesa de uma formação linguística de qualidade para professores de línguas estrangeiras: o exame EPPLE ${ }^{1}$
}

\author{
Douglas Altamiro Consolo \\ UNESP São José do Rio Preto \\ dconsolo@terra.com.br \\ Vera Lúcia Teixeira da Silva \\ UERJ / ISAT \\ veraldasilva@yahoo.com.br
}

\section{Resumo}

Neste artigo apresentamos as justificativas para um exame de proficiência linguístico-comunicativo-pedagógica específico para professores de línguas estrangeiras no cenário brasileiro. Relatamos o trajeto histórico de atividades acadêmicas e de pesquisas desde o surgimento das ideias que motivaram nossa proposta, dentre as quais eventos nos quais a proposta foi apresentada, dissertações e teses - defendidas e em andamento - e ações mais recentes para a implementação do exame em maior escala. Com a implementação e disponibilização do EPPLE, espera-se que se (re)definam os objetivos e a metodologia do ensino das línguas estrangeiras nos cursos de formação de professores, ou seja, que os resultados das investigações e das aplicações do exame sejam revertidos para o aprimoramento da formação nos cursos de Letras no Brasil e tragam contribuições para pesquisas na área de avaliação de línguas.

Palavras-chave: Avaliação. Língua estrangeira. Proficiência linguística. Formação de professores.

\footnotetext{
${ }^{1}$ Agradecemos a participação de Aline Mara Fernandes pelo texto preliminar de descrição da natureza do EPPLE.
} 


\section{Abstract}

In this article, we argue in favour of an examination of linguisticcommunicative-pedagogic proficiency for foreign language teachers in the Brazilian context. A historical line of academic activities and research studies related to the proposal for this examination, since the initial ideas that have motivated our engagement in the project, is reported, which includes academic events where the proposal was presented, MA theses and $\mathrm{PhD}$ dissertations in which preliminary research data have been analysed, and other recent actions towards the implementation of the examination. Once the EPPLE examination is largely available, it is expected that the aims and the teaching methodology for foreign languages in teacher education courses be revised, that is, the research results based on data about the examination are expected to contribute towards improvements in teacher education Letters courses in Brazil, as well as provide contributions for the areas of language assessment and testing.

Keywords: Assessment. Foreign languages. Language proficiency. Teacher education.

\section{Introdução}

A proficiência linguística ocupa papel essencial no perfil profissional do professor de língua estrangeira (LE), conforme já apontado por estudiosos da área da Linguística Aplicada (por exemplo, ALMEIDA FILHO, 1992; BAFFI-BONVINO, 2010; BORGES ALMEIDA, 2009; QUEVEDO-CAMARGO, 2011). Neste artigo, propomo-nos a tratar da questão da proficiência linguística de professores de LE, sob o prisma da avaliação e seu potencial de impacto e de efeito retroativo nos processos de ensino e de aprendizagem. Nesse sentido, apresentamos um instrumento para avaliação dessa proficiência como produto de pesquisas e embasado em dados coletados no contexto brasileiro de formação de professores de LE. Esse instrumento, que se configura como um exame para avaliar a proficiência em LE de professores pré-serviço e de professores em exercício - nas habilidades escritas e orais-pode vir a tornar-se uma ferramenta valiosa para com ela se interferir positivamente no cenário de ensino e de aprendizagem de línguas.

Desde o final da década de noventa, os pesquisadores pertencentes ao grupo de pesquisa Ensino e Aprendizagem de Língua 
Estrangeira: crenças, construtos e competências (ENAPLE-CCC) vêm trabalhando no desenvolvimento de um exame que dê conta de avaliar a proficiência linguístico-comunicativo-pedagógica (PLCP)de professores responsáveis pelo ensino de línguas estrangeiras, denominado Exame de Proficiência para Professores de Línguas Estrangeiras (EPPLE), a partir de dados teóricos e experimentais, da literatura e de testes de proficiência existentes tanto no Brasil quanto no exterior. Buscam-se, nos exames internacionais e pesquisas a eles relacionadas, subsídios à elaboração do EPPLE, visando a delimitar o construto do exame, os tipos de tarefas pertinentes à avaliação das habilidades linguísticas dos professores e os parâmetros a serem considerados na avaliação da proficiência linguística desejada para esses profissionais.

\section{A respeito da proposta de um exame de proficiência para professores de LE}

Apresentamos, nesta seção, os aspectos mais gerais da proposta de implementação do EPPLE.

O critério de avaliação de proficiência linguística, no seu sentido mais amplo, deve ser holístico- tomando por base o desempenho global do examinado durante as partes do exame- e ter uma visão integrada dos componentes da linguagem. Ou seja, existe uma influência e interdependência entre os componentes delimitados nos descritores propostos para o EPPLE. Essa visão se alinha com o conceito de Hymes (1971, p. 19; 1972, p. 279) de "competência de uso" (competence for use) de uma língua. Segundo esse autor,

Há regras de uso sem as quais as regras de gramática seriam inúteis. Da mesma maneira que regras de sintaxe podem controlar aspectos fonológicos, e regras de semântica talvez controlem aspectos de sintaxe, assim regras de atos de fala controlam a totalidade das formas linguísticas (HYMES, 1972, p. 278). ${ }^{2}$

\footnotetext{
${ }^{2}$ No original: "There are rules of use without which the rules of grammar would be useless. Just as rules of syntax can control aspects of phonology,
} 
Apresentamos, em anexo, uma proposta preliminar de faixas de proficiência para o teste oral do EPPLE, nas quais se pode verificar como se constitui uma grade de cinco níveis para avaliação da linguagem do professor de LE, pensando-se, também, para cada faixa, um critério holístico dessa proficiência. Essa averiguação holística efetiva-se por meio dos descritores elencados, com base em critérios mais analíticos dos aspectos da linguagem considerados comunicação e interação, pronúncia, precisão e complexidade gramatical, amplitude e adequação lexical, além de características da linguagem pedagógica e a compreensão oral. Nas faixas de proficiência descrevem-se tanto os aspectos linguísticos como algumas das competências desejadas no desempenho oral do candidato.

As discussões sobre os descritores para os componentes da linguagem na avaliação da proficiência oral no EPPLE avançaram mais do que aquelas sobre as proficiências de leitura e de produção escrita, pois mais pesquisas são realizadas sobre dados orais, com base no desenho do Teste de Proficiência Oral em Língua Inglesa (TEPOLI) (CONSOLO, 2004; CONSOLO; TEIXEIRA DA SILVA, 2007). Fazse necessário avançar também nas investigações sobre o teste escrito do EPPLE, para definição de descritores e de faixas de proficiência embasadas tanto em critérios analíticos como em critérios holísticos, com base em estudos específicos sobre a proficiência de professores nas habilidades escritas, de modo semelhante - em abrangência e com base em dados coletados sobre as habilidades escritas -aos critérios de avaliação das habilidades orais. Necessita-se, portanto, empenho na trajetória de investigar, avaliar e definir a PLCP em LE também em termos de um escopo de competência linguística mais ampla ou geral, bem como em termos de uma proficiência para o uso da linguagem oral para a finalidade específica de atuar como professor da língua ensinada (DOUGLAS, 2000; ELDER, 1994a, 2001), incluindo-se aqui a linguagem pedagógica ou metalinguagem.

Neste ponto, cabe, como justificativa para esta proposta, mencionar a existência de exames e testes de proficiência consagrados

and just as rules of semantic perhaps control aspects of syntax, so rules of speech acts enter as a controlling factor for linguistic form as a whole." 
(ETPC), para avaliação, por exemplo, da proficiência em língua inglesa (LI), produzidos por organizações especializadas em avaliação e reconhecidas internacionalmente, tais como os exames de Cambridge ESOL $^{3}$ (Inglaterra) e o teste $\mathrm{TOEFL}^{4}$ (EUA), dentre os mais conhecidos e utilizados no Brasil. Sem desconsiderarmos as contribuições desses ETPC e das organizações nas quais esses exames internacionais são produzidos - tanto na criação dos ETPC quanto na implementação dos mesmos no cenário mundial e também no Brasil, preocupamo-nos, contudo, com os aspectos de validade desses exames na área específica da proficiência linguística de professores de línguas estrangeiras. Na visão da equipe de pesquisadores envolvidos na produção e na implementação do EPPLE, com base em argumentações sobre avaliação para fins específicos e sobre implicações sociais da avaliação (por exemplo, DOUGLAS, 2000; McNAMARA, 2000, 2005; SHOHAMY, 2001), algumas críticas à utilização dos ETPC de modo amplo, para toda e qualquer finalidade de avaliação de proficiência, podem ser apontadas.

ETPC constituem exemplos típicos da "força" de exames e testes de alto impacto social (em inglês, high-stakestests), e sua utilização, bem como dos resultados obtidos por candidatos, devem ser utilizados coma finalidade para a qual esses instrumentos foram pensados, respeitando sua validade de construto e de conteúdo.

Conforme apontado por Martins (2005), e preocupados com a avaliação na área de Licenciatura em Letras, e nas habilitações em línguas estrangeiras, bem como com as políticas de formação e de avaliação profissional no contexto brasileiro, vemos a necessidade da discussão dessas questões, partindo-se "das necessidades linguísticas de professores de (I)LE no Brasil” (CONSOLO, 2005a, p. 282). Nessa perspectiva, procedem as investigações na direção de se tratarem as questões de caráter terminológico, teórico e metodológico para a efetiva implementação do EPPLE, foco de diversos projetos de pesquisa concluídos (por exemplo, BUSNARDI, 2012; CONSOLO, 2008; SILVA NETO, 2013;) e de outros em andamento (por exemplo,

\footnotetext{
${ }^{3}$ English for Speakers of Other Languages (para maiores informações, acessar www.cambridgeesol.org).

${ }^{4}$ Test of English as a Foreign Language (ibid, www.ets.org/toefl).
} 
ANDRELINO, 2012; FERNANDES, 2012; COLOMBO, 2012; CONSOLO, 2011). O projeto de Consolo (2011) consiste numa continuidade de um projeto em desenvolvimento, desde 2008, tendo sido, entretanto, formalizado como projeto distinto para adequação ao plano trienal de atividades do pesquisador-coordenador, no período de 2011 a 2013.

O projeto de Busnardi (op. cit.) trata da questão da precisão e da complexidade gramatical na linguagem oral de quatro professoras de LI formadas em um curso de licenciatura em Letras no estado de São Paulo. O projeto trienal de Consolo (2008) contribuiu para o andamento das investigações conduzidas no período 2008-2012, no escopo de trabalhos de iniciação científica, dissertações de mestrado e teses de doutorado. Nesses trabalhos, os autores refletiram e analisaram dados de proficiência oral de professores e de alunos de licenciatura em Letras, por exemplo, do TEPOLI. Silva Neto (op. cit.) analisou o léxico em testes orais do EPPLE, coletados em três anos consecutivos da aplicação do exame no mesmo contexto universitário da investigação de Busnardi, e apresenta uma discussão sobre as ocorrências lexicais nas falas dos examinandos e os critérios de avaliação de vocabulário nas faixas de proficiência oral do exame.

Almeja-se a implementação do EPPLE no cenário nacional, para que se tenha um instrumento válido e confiável que atenda os objetivos de uma avaliação de proficiência efetivamente linguísticocomunicativa-pedagógica de professores (KOL, 2009; MARTINS, 2005; QUEVEDO-CAMARGO, 2011), embasada em pesquisas que iluminam o construto do exame (por exemplo, BAFFI-BONVINO, 2010; BORGES-ALMEIDA, 2009; DUCATTI, 2010; FERNANDES, 2011), principalmente em sua versão para meios eletrônicos (ANCHIETA, 2010).

Verifica-se a necessidade de descrever mais criteriosamente a PLP do (recém-) licenciado, a qual pode variar de um nível minimamente exigido, para que o professor possa atuar profissionalmente, até um nível superior, almejado para alunos que demonstrem uma PLP de excelência. Para essa descrição, é necessária a construção de faixas de proficiência tanto para as habilidades escritas quanto para as habilidades orais, com base em descritores dos níveis de linguagem considerados, a saber: gramática e estrutura sintática, vocabulário, pronúncia, fluência, estratégias de interação verbal, 
habilidade de leitura e habilidade de produção escrita, entre outros. As faixas de proficiência devem também apontar critérios embasados nas competências de uso da LE.

Faz-se necessário, portanto, (a) aprimorar a delimitação do domínio da linguagem do professor de LE, nos contextos de ensino de línguas no Brasil, e decorrente dessa delimitação, definir os recortes linguísticos a serem considerados em critérios de avaliação da PL desse professor; (b) refinar os critérios de avaliação da PLCPP, incorporando-os em faixas de proficiência (CONSOLO, 2004; CONSOLO \& TEIXEIRA DA SILVA, 2007) de caráter holístico e analítico, para que incluam, além de características linguísticas, tarefas a serem desempenhadas pelo professor de ILE por meio da linguagem; e (c) implementar tarefas que melhor se prestem a avaliar a PLCPde professores no âmbito de um exame de proficiência que contemple as quatro habilidades de uso da LE (compreensão e produção, escrita e oral), necessárias a esses profissionais.

Finalmente, outra questão que se coloca é a da viabilidade de se aplicar um exame a candidatos de diversas regiões do país, dada a sua grande extensão geográfica. Entre as limitações, temos o custo do deslocamento de examinadores ou de candidatos. Pretendemos, então, desenvolver um exame aplicado eletronicamente.

De acordo com Chapelle e Douglas (2006), seria difícil estimar, atualmente, quantos aprendizes de outras línguas prestaram ou prestarão testes aplicados por computador. Esse número cresce rapidamente, ou seja, a realidade dos testes aplicados por meios eletrônicos encontra-se em expansão. Os mesmos autores afirmam também que, conforme demonstrado por pesquisas e pela prática, o uso da tecnologia expande e modifica as exigências conceituais e práticas para os envolvidos em avaliação eletrônica. Isso justifica maior conhecimento dessas demandas na área de Linguística Aplicada.

As vantagens de testes computadorizados são inúmeras. Entre elas, pode-se citar a possibilidade de adaptarem questões ao nível de proficiência de um candidato, com base em suas primeiras respostas, obtendo-se assim quase que um teste "individualizado".Computadores oferecem uma diversidade de insumos multimodais, como texto escrito, som, imagens fotográficas e vídeos, enriquecendo assim tanto a autenticidade situacional dos insumos como das respostas, em determinados casos interativas, dos candidatos. Além disso, testes e 
exames em meio eletrônico possibilitam o conhecimento imediato dos resultados e, quanto a sua aplicação, adequam-se à disponibilidade do candidato.

Dadas as vantagens de testes e exames aplicados em meios eletrônicos, o EPPLE foi desenvolvido como um exame que pode ser disponibilizado por computador, a distância, ou em modo presencial, uma vez que nem sempre as instituições oferecem condições adequadas para a realização dos testes e exames em meio eletrônico. Os problemas mais frequentes dizem respeito ao número insuficiente de computadores e até mesmo à falta deles, a conexões de internet lentas, à falta de competência tecnológica de muitos candidatos, entre outros.

\section{O EPPLE: Um breve histórico}

A primeira proposta do EPPLE, feita publicamente, ocorreu durante a XV Jornada de Ensino de Língua Inglesa (JELI) em 1999. $\mathrm{Na}$ ocasião, as atividades do referido projeto eram coordenadas pelo professor José Carlos Paes de Almeida Filho (Unicamp). ${ }^{5}$ Participavam da equipe de trabalho alguns membros da equipe atual, entre os quais Douglas Altamiro Consolo, Hélcio de Pádua Lanzoni, Magali Barçante, Teresa Helena Buscato Martins e Vera Lúcia Teixeira da Silva, além de outros que posteriormente se desligaram do projeto.

Em 2001, a equipe apresentou, no Congresso Brasileiro de Linguística Aplicada (CBLA), uma seção de comunicações integradas sobre a proposta do exame. Uma das comunicações - intitulada "A Necessidade de um Exame de Proficiência para Professores de Língua Estrangeira/Inglês (EPPLE/Inglês)"-foi apresentada por Edcléia Basso (UNIEPAR) e Magali Barçante (UNIMEP). Nessa comunicação, trataram-se das competências esperadas de um professor de língua estrangeira, entre elas a capacidade de usar a língua ensinada, a CLC. Por não ser claramente descrita na literatura especializada em avaliação de proficiência e pela falta de indicações de quais são os

${ }^{5}$ Instituições dos membros da equipe do projeto nas datas mencionadas no texto. 
níveis desejados para alunos ingressantes e formandos dos cursos de Letras no Brasil, a equipe do EPPLE-visando estudar e encaminhar soluções para o assunto no cenário brasileiro - propôs explicitar a magnitude da necessidade e as repercussões do então estado de proficiência demonstrado por professores nos ensinos fundamental e médio. Nessa mesma sessão, sob o título "Exame de Proficiência para Professores de Língua Estrangeira (EPPLE/Inglês): análise de necessidades e níveis de proficiência”, Matilde Virginia Ricardi Scaramucci (Unicamp) e Hélcio de Pádua Lanzoni (Unaerp) destacaram a necessidade de se elaborar um modelo de análise das necessidades de uso da língua-alvo, na sala de aula e em outros contextos profissionais onde se discutem os processos de ensinoaprendizagem de LE para serem, então, traduzidas, por meio de taxonomia específica, em níveis de desempenho balizados por um nível limiar profissional. Para descrever esse nível limiar de proficiência, apresentaram-se uma amostra das categorias e exemplos de tarefas que poderiam constar do instrumento de avaliação.

Douglas Altamiro Consolo (Unesp) e Vera Lúcia Teixeira da Silva (Uerj) apresentaram o trabalho "Mapeando a Competência Linguístico-Comunicativa de Alunos de Letras-Língua Inglesa: definição de um construto para a formação de professores". $\mathrm{Na}$ ocasião, discutiram como o conceito de proficiência oral- a partir de construtos levantados na literatura e dados de contextos de formação de professores de inglês como língua estrangeira - pode configurar-se para o estabelecimento de um perfil da CLC nessa LE. Foram contrastadas as características das proficiências almejada e atingida de alunos de licenciatura em Letras, segundo avaliações formais e visões de alunos e professores. Algumas dificuldades enfrentadas pelos alunos no processo de aprendizagem de língua inglesa em relação à competência oral e diante das expectativas de formação profissional também foram abordadas.

José Carlos Paes de Almeida Filho (Unicamp) e Edley Matos dos Santos (Instituto Adventista de Ensino, Engenheiro Coelho/SP) apresentaram a comunicação "Questões de implementação do EPPLE". Destacaram a importância do respaldo que um exame de proficiência voltado para as necessidades e para as obrigações profissionais de LE precisa receber de uma organização ou entidade institucional. Essa vinculação visa a garantir a continuidade dos interesses do corpo 
profissional na manutenção dos níveis profissionais de desempenho esperados dos professores de LE nos estados do Brasil. Discutiram-se, ainda, algumas características básicas da implementação e gestão do exame em uma ou duas ocasiões ao ano, os termos da certificação e sua natureza inicialmente opcional.

Em 2002, a equipe do EPPLE, ainda coordenada pelo Prof. Dr. José Carlos Paes de Almeida Filho, participou da XVIII JELI. Integravam a equipe, nesse ano, os professores doutores Douglas Altamiro Consolo, Edcléia Basso, Magali Barçante, Matilde Scaramucci e Vera Lúcia Teixeira da Silva (UERJ). O título da comunicação foi "A Construção do Exame de Proficiência em Língua Estrangeira/Inglês (EPLE-Inglês)”. O objetivo foi mostrar um protótipo do instrumento em construção, situando as premissas e justificativas para as decisões tomadas. Dado que o exame está caracterizado como de base comunicativa, discutiram-se os principais pressupostos teóricos que o sustentam, assim como algumas das implicações práticas e políticas que a oferta do instrumento produziria entre os professores de inglês do estado de São Paulo, quando fosse introduzido. A equipe contemplava as seguintes frentes de trabalho: estado atual de proficiência do professor de LE (inglês) nas escolas; análise das necessidades linguístico-comunicativas e sua tradução em faixas de desempenho; definição de um construto operacional de competências do professor; elaboração do instrumento de avaliação propriamente dito; procedimentos e condições de implementação do EPPLE.

Em 2008, durante o II CLAFPL (Congresso Latino-Americano de Formação de Professores de Línguas), realizado na PUC-Rio, a equipe do EPPLE apresentou uma sessão de comunicações coordenadas intitulada "Subsídios para Elaboração de um Exame de Proficiência para Professores de Inglês". Na ocasião, integravam a equipe Douglas Altamiro Consolo, como coordenador do projeto (Unesp/SJRP), Hélcio de Pádua Lanzoni (Unaerp), Magali Barçante (Fatec e Unimep), Marcelo Concário (Unaerp), Teresa Helena Buscato Martins (Unip) e Vera Lúcia Teixeira da Silva (Uerj). Um histórico do Projeto EPPLE foi apresentado no II CLAFPL, como segue: XV JELI -Jornada de Ensino de Língua Inglesa - 1999; VI Congresso Brasileiro de Linguística Aplicada - 2001; XVIII JELI - 2002; assim como apresentações em eventos no exterior (Austrália, Canadá e Alemanha). 
A equipe justificou a necessidade de um exame de proficiência por ser: uma certificação; uma contribuição para a carreira do professor, fornecendo um parâmetro (benchmark, ELDER, 1994a) para seu crescimento profissional e pessoal; um plano de carreira e uma revisão de seu desempenho; e uma forma de promover a imagem pública do ensino de inglês como língua estrangeira. Destaca-se, também: que a CLC não é descrita na literatura especializada, não havendo indicações de níveis de proficiência desejados; a necessidade de se intervir no cenário de formação de professores de línguas no Brasil e a inexistência de qualquer exame brasileiro desenvolvido e amplamente utilizado especificamente para professores. A equipe, nessa data, ocupava-se: em pilotar o EPPLE, criando tarefas para avaliar compreensão e produção oral e escrita; em descrever níveis de competência que serão usados na correção do teste e na divulgação dos resultados; em descrever e testar os critérios de correção adequados aos vários tipos de tarefa que poderão compor o teste e coletar e analisar dados que promovam o aperfeiçoamento contínuo do EPPLE. O conteúdo dessa sessão de comunicações foi publicado, em texto único, nos anais do II CLAFPL, em 2010.

No II Congresso Internacional da ABRAPUI (Associação Brasileira de Professores Universitários de Inglês), em São José do Rio Preto, no ano de 2009, a equipe do EPPLE apresentou a comunicação coordenada "Exame de Proficiência para Professores de Línguas Estrangeiras (EPPLE): pressupostos e procedimentos de avaliação", coordenada pelo professor Douglas Altamiro Consolo. Integraram a comunicação os trabalhos "Subsídios para elaboração de um exame de proficiência para professores de inglês", "A avaliação da leitura e da produção de textos no exame EPPLE: critérios de elaboração e correção" e "Tarefas e critérios para avaliação de proficiência oral de professores de língua estrangeira".

Em 2010 foi criada a página eletrônica do EPPLE, <http://www.epplebrasil.org/>. Também em 2010 outras professoraspesquisadoras passaram a integrar a equipe do projeto do EPPLE, a qual é atualmente constituída por dez pesquisadores, de seis instituições brasileiras (Fatec, Fef, Uerj, UnB, Unesp, Uniseb).

Ainda em 2010, promoveu-se o I SEMAPLE - Seminário de Avaliação de Proficiência de Línguas Estrangeiras - na Universidade Federal de São Carlos, que contou com a presença de vários estudiosos 
da área de avaliação e no qual pesquisas nessa área foram apresentadas e discutidas em palestras, mesas-redondas e comunicações orais. Em 2013 realizou-se o II SEMAPLE na unidade da FATEC de Indaiatuba.

Em 2012, durante o III Congresso Internacional da ABRAPUI, realizado na UFSC, em Florianópolis, dois momentos envolveram o EPPLE, um trabalho em uma mesa-redonda, apresentado por Vera Lucia Teixeira da Silva, intitulado "O Exame EPPLE: Desafios na implementação de um exame eletrônico", e uma sessão de comunicações coordenadas, intitulada "Avaliação de proficiência oral de professores de língua inglesa: contribuições à validação do EPPLE, coordenada por Elen Dias (FEF).

Oportunamente deverá ser publicado um livro sobre perspectivas em avaliação no ensino e na aprendizagem de línguas, no qual serão abordadas pesquisas brasileiras, algumas sobre dados preliminares do EPPLE, e encaminhamentos na prática docente, contendo capítulos escritos por estudiosos que há anos vêm se debruçando em questões relativas à área de avaliação no ensino e aprendizagem de línguas. No Brasil, essa área ainda carece de mais estudos e pesquisas.

\section{A natureza do EPPLE}

O Exame de Proficiência para Professores de Línguas Estrangeiras avalia as habilidades de compreensão e de produção em língua estrangeira, nas modalidades escrita e oral. Trata-se de um exame comunicativo que objetiva avaliar a proficiência linguística escrita e oral do candidato em termos de usos da língua que refletem situações reais de comunicação, incluindo-se a comunicação entre professores e seus alunos. Durante o exame, o candidato deve desempenhar tarefas que se assemelham àquelas realizadas nos contextos de aulas de línguas estrangeiras. Por ser um exame para fins específicos, o EPPLE busca aferir a capacidade de uso da língua estrangeira, o que envolve conhecimentos de regras de comunicação e de formas socialmente aceitas, e conhecimentos sobre a língua, constituintes de uma competência metalinguística, o que configura o domínio específico de linguagem do professor de LE. 
O exame é composto de dois testes distintos, um de leitura e produção escrita, e um de compreensão e produção oral. O teste escrito contém questões de compreensão de textos de interesse de professores de línguas, e questões nas quais o candidato deve realizar tarefas verossímeis à produção escrita de professores - por exemplo, redigir perguntas para uma atividade de compreensão de leitura e fazer correções em textos produzidos por alunos. Tarefas que exijam a produção de textos argumentativos, ou de resumos de textos acadêmicos, também podem ser contempladas. O teste oral contém três partes. Na primeira, solicita-se que o examinando fale sobre si mesmo, na perspectiva de aluno e falante-usuário da língua estrangeira sendo avaliada e, conforme as experiências do candidato, também enquanto professor dessa língua. Na segunda parte do teste oral apresenta-se um breve excerto de vídeo, baseado no qual o candidato responde questões sobre seu tema e conteúdo. Na terceira parte do teste os candidatos devem demonstrar sua proficiência no uso de metalinguagem, ou seja, da linguagem específica para atuação pedagógica. Apresentam-se problemas de cunho realista enfrentados por alunos, sobre aspectos da língua estrangeira em questão, para os quais os examinandos devem oferecer explicações e soluções.

A proficiência é avaliada por meio de descritores que constituem níveis representados em uma escala, com variação de A (faixa superior) a E (faixa inferior). Propõe-se o estabelecimento de escalas de caráter mais analítico para cada um dos dois testes e de uma escala de caráter holístico para classificação do desempenho global do candidato no EPPLE.

\section{A implementação do EPPLE no Brasil}

Versões preliminares dos testes escrito e oral do EPPLE vêm sendo aplicadas a alunos-formandos em cursos de licenciatura em Letras com habilitação em Língua Inglesa (LI), desde 2009, e os dados coletados por meio desses testes encontram-se sob análise pelo grupo atual de pesquisadores e seus orientandos. Em um desses cursos, já se percebe um efeito retroativo do exame, por exemplo, na preocupação em se tratar mais especificamente da linguagem pedagógica e de oportunizar aos alunos a prática oral de fornecer explicações, de 
caráter linguístico, sobre a LI, competência essa avaliada em uma das tarefas do EPPLE.

Em 2011 foi elaborada uma versão do EPPLE inteiramente eletrônica, contendo os dois testes, oral e escrito. Essa versão está sendo aplicada, em caráter piloto, nas universidades nas quais os pesquisadores do projeto do exame atuam como docentes. ${ }^{6}$ Pretende-se analisar os dados coletados por meio dessa versão eletrônica do exame, bem como elaborar outras versões, para aprimoramento em futuras aplicações.

Necessita-se, neste momento, apoio financeiro ${ }^{7}$ e logístico para que o EPPLE possa ser produzido e disponibilizado em escala maior, e podermos então verificar sua eficiência enquanto instrumento de avaliação da PLP, bem como suas repercussões e o possível surgimento de efeitos retroativos no cenário brasileiro.

Espera-se que, com a implementação e disponibilização do EPPLE, se (re)definam mais claramente os objetivos do ensino das línguas estrangeiras nos cursos de formação de professores, para que os resultados das investigações e das aplicações do exame sejam revertidos para o aprimoramento da formação docente, nos cursos de Letras oferecidos no Brasil, além de contribuições para pesquisas na área de avaliação de línguas. Os níveis de proficiência propostos no EPPLE podem também pautar critérios de certificação e de contratação de professores, sem representar necessariamente um impedimento à atuação desses profissionais, mas sim uma referência de qualidade no ensino de LE no cenário nacional.

\footnotetext{
${ }^{6}$ A primeira aplicação ocorreu na UnB, em 14/10/2011, e outras aplicações estão previstas para a UERJ e para a UNESP ainda em 2011.

${ }^{7}$ Projetos de Iniciação Científica, em desenvolvimento no âmbito do projeto de Consolo (2011), receberam bolsas PIBIC. O projeto de Busnardi (em andamento) tem apoio de bolsa de mestrado da CAPES. O projeto maior do exame, entretanto, ainda não possui apoio financeiro.
} 
Douglas A. Consolo; Vera Lúcia Teixeira da Silva

\section{Referências}

ALMEIDA FILHO, José Carlos P. O professor de língua estrangeira sabe a língua que ensina? Contexturas, v.1, n. 1, p. 77-85, 1992.

ALONSO, Myrtes. Prefácio. In: COSTA, Daniel N. M., Por que ensinar língua estrangeira na escola de $1^{\circ}$ grau, São Paulo: EPUEDUC, 1987. p. XIII-XIV.

ANCHIETA, Priscila P. Análise de testes de proficiência em língua inglesa: subsídios à elaboração de um exame para professores de inglês no brasil. 2010. Dissertação (Mestrado em Estudos Linguísticos) - Instituto de Biociências, Letras e Ciências Exatas, UNESP, São José do Rio Preto, 2010.

ANJOS, Flavius A. Qual a verdadeira finalidade do ensino da língua inglesa na escola? SALA: Linguística Aplicada, Cultura Digital $e$ Educação. Disponível em: <http://www.sala.org.br/textos-em-la>. Acesso em 1 nov. 2011.

BAFFI-BONVINO, Melissa A. Avaliação da proficiência oral em inglês como língua estrangeira de formandos em letras: uma proposta para validar o descritor 'vocabulário' de um teste de professores de língua inglesa. Tese (Doutorado em Estudos Linguísticos) - Instituto de Biociências, Letras e Ciências Exatas, UNESP, São José do Rio Preto, 2010.

BAGHIN-SPINELLI, Débora C. M.. Ser professor (brasileiro) de língua inglesa: um estudo dos processos identitários nas práticas de ensino. Tese (Doutorado em Linguística Aplicada). Campinas: UNICAMP, 2002.

BASSO, Edcleia A. Quando a crença faz a diferença. In: BARCELOS, Ana Maria F.; VIEIRA-ABRAHÃO, Maria Helena (Org.). Crenças $e$ ensino de línguas: foco no professor, no aluno e na formação de professores. Campinas: Pontes Editores, 2006. p. 65-85.

BENEDETTI, Ana Mariza; CONSOLO, Douglas A.; VIEIRAABRAHÃO, Maria Helena (Org.). Pesquisas em ensino $e$ 
Em defesa de uma formação linguística...

aprendizagem no Teletandem Brasil: línguas estrangeiras para todos. Campinas: Pontes Editores, 2010.

BERGER FILHO, Ruy L.; PEREIRA, Avelino R. S.; MAIA, Eny Marisa. Parâmetros Curriculares Nacionais - Ensino Médio. (mimeo)

BORGES-ALMEIDA, Vanessa. Precisão e complexidade gramatical na avaliação de proficiência oral em inglês do formando em letras: implicações para a validação de um teste. Tese (Doutorado em Linguística Aplicada) - Instituto de Biociências, Letras e Ciências Exatas, UNESP, São José do Rio Preto, 2009.

BRASIL. Parâmetros Curriculares Nacionais: terceiro e quarto ciclos do ensino fundamental/língua estrangeira. Brasília: MEC/SEF, 1998.

BUSNARDI, Bruna. Precisão e complexidade gramatical na proficiência oral do professor de inglês como língua estrangeira. Dissertação (Mestrado em Estudos Linguísticos) - Instituto de Biociências, Letras e Ciências Exatas, UNESP, São José do Rio Preto, 2012.

CAMARGO, Gladys P. Q. Exame internacional para professores de inglês: uma análise na perspectiva sócio-interacionista. Dissertação (Mestrado em Letras). Londrina: UEL, 2007.

CANALE, Michael. From communicative competence to communicative language pedagogy. In: RICHARDS, Jack; SCHMIDT, Richard. W. (Org.). Language and communication. Harlow: Longman, 1983. p. 2-26.

CHAPELLE, Carol A.; DOUGLAS, Dan. Assessing language through computer technology. Cambridge: Cambridge University Press, 2006.

CONSOLO, Douglas A. Avaliação da proficiência linguísticocomunicativa-pedagógica do professor de línguas: operacionalização de construto no Exame de Proficiência para Professores de Língua Estrangeira (EPPLE). Projeto trienal de pesquisa. São José do Rio Preto: UNESP, 2011. 
Douglas A. Consolo; Vera Lúcia Teixeira da Silva

- Exame de Proficiência para Professores de Língua Estrangeira (EPPLE): definição de construto, tarefas e parâmetros para avaliação em contextos brasileiros. Projeto trienal de pesquisa. São José do Rio Preto: UNESP, 2008.

- Avaliação de proficiência oral: uma reflexão sobre instrumentos e parâmetros na formação do (futuro) professor de língua estrangeira. In: ALVAREZ, Maria Luisa O.; SILVA, Kleber A. (Org.). Linguística Aplicada: múltiplos olhares. Brasília: Universidade de Brasília; Campinas: Pontes Editores, 2007a. p. 109-118.

A competência oral de professores de língua estrangeira: a relação teoria-prática no contexto brasileiro. In ; TEIXEIRA DA SILVA, Vera Lúcia (Org.). Olhares sobre competências do professor de língua estrangeira: da formação ao desempenho profissional. São José do Rio Preto: Editora HN, 2007b. p. 165-178.

- On a (re)definition of oral language proficiency for EFL teachers: Perspectives and contributions from current research. Melbourne Papers in Language Testing, p. 1-28, 2006.

. Posturas sobre avaliação da proficiência oral do professor de língua estrangeira: implicações para o cenário brasileiro. In FREIRE, Maximina Maria; VIEIRA-ABRAHÃO, Maria Helena; BARCELOS, Ana Maria F. (Org.). Lingüística Aplicada e contemporaneidade. Campinas: Pontes; São Paulo: ALAB, 2005a. p. 269-287.

- Competência lingüística em língua inglesa de alunos de letras: definição de parâmetros na formação $e$ avaliação da proficiência oral do professor de língua estrangeira. Projeto trienal de pesquisa. São José do Rio Preto: UNESP, 2005b.

A construção de um instrumento de avaliação da proficiência oral do professor de língua estrangeira. Trabalhos em Linguística Aplicada, v. 43, n. 2, p. 265-286, 2004.

Competência linguiístico-comunicativa: (re)definindo o perfil do professor de língua estrangeira. In: VI CONGRESSO 
Em defesa de uma formação linguística...

BRASILEIRO DE LINGUÍSTICA APLICADA. Belo Horizonte: UFMG, 2002. CD-ROM.

- A (In)Competência linguístico-comunicativa de alunos de letras-língua estrangeira: construto e tendências na Formação do Professor. Projeto trienal de pesquisa. São José do Rio Preto: UNESP, 2001.

- Revendo a oralidade no ensino/aprendizagem de línguas estrangeiras. Revista de Estudos Universitários, v. 26, n. 1, p. 59-68, 2000 .

. On teachers' linguistic profiles and competence: implications for foreign language teaching. In: XIV ENPULI. Belo Horizonte: Universidade Federal de Minas Gerais, 1999, p. 123-134.

. et al. Exame de Proficiência para Professores de Língua Estrangeira (EPPLE): proposta inicial e implicações para o contexto brasileiro. In: II Congresso Latino-Americano de Formação de Professores de Línguas (CLAFPL). Rio de Janeiro: PUC-Rio, 2010. CD-ROM.

; TEIXEIRA DA SILVA, Vera Lúcia. The TEPOLI test: construct, updated tasks and new parameters to assess EFL teachers' oral proficiency. In: I Congresso Internacional da ABRAPUI. Belo Horizonte: UFMG, 2007. CD-ROM.

COSTA, Daniel N. M. Por que ensinar língua estrangeira na escola de $1^{\circ}$ grau. São Paulo: EPU-EDUC, 1987.

DIAS, Elen. Avaliação: meio para intervenção pedagógica na formação do professor de língua estrangeira e (re)construção da sala de aula. Tese (Doutorado em Estudos Linguísticos) - Instituto de Biociências, Letras e Ciências Exatas, UNESP, São José do Rio Preto, 2011.

DOUGLAS, Dan. Assessing languages for specific purposes. Cambridge: Cambridge University Press, 2000. 
Douglas A. Consolo; Vera Lúcia Teixeira da Silva

DUCATTI, Ana Lúcia F. A interação verbal e a proficiência oral na língua-alvo na prática de sala de aula: (re)definindo o perfil do professor de uma professora de língua inglesa da escola pública. Dissertação (Mestrado em Estudos Linguísticos) - Instituto de Biociências, Letras e Ciências Exatas, UNESP, São José do Rio Preto, 2010.

ELDER, Catherine. Assessing the language proficiency of teachers: are there any border controls? Language Testing, v. 18, n. 2, p. 149170, 2001.

- Performance testing as benchmark for foreign language teacher education. Babel. Journal of the Federation of Modern Language Teachers Associations, v. 29, n. 2, p. 9-19, 1994a.

- Are raters' judgements of language teacher effectiveness wholly language based? Melbourne Papers in Language Testing, v. 3, n. 2, p. 41-61, 1994b.

FERNANDES, Aline Mara. A metalinguagem e a precisão gramatical na proficiência oral de duas professoras de inglês como língua estrangeira. Dissertação (Mestrado em Estudos Linguísticos) Instituto de Biociências, Letras e Ciências Exatas, UNESP, São José do Rio Preto, 2011.

HYMES, Dell. Competence and performance in linguistic theory. In HUXLEY, R.; INGRAM, E. (Org.) Language acquisition: models and methods. New York: Academic Press, 1971.

. On communicative competence. In PRIDE, John Bernard. HOLMES, Janet. (Org.) Sociolinguistics. Harmondsworth: Penguin, 1972.

KAMHI-STEIN, Lia. The relationship between English-as-a-foreign language teacher proficiency and language use in the classroom. Cadernos de Letras, v. 27, p. 93-100, 2010.

KOL, José Paulo T. Avaliando as Competências dos Professores de Língua Estrangeira (Inglês): um estudo sobre a validade de uma 
Em defesa de uma formação linguística...

certificação internacional. Dissertação (Mestrado em Linguística Aplicada) - Instituto de Letras, UnB, Brasília, 2009.

LEFFA, Vilson José. "Pra que estudar inglês, profe?" Auto-exclusão em língua estrangeira. Claritas, v. 13, n. 1, p. 47-65, 2007.

MARTINS, Teresa Helena Buscato. Subsídios para a Elaboração de um Exame de Proficiência para Professores de Inglês. Dissertação (Mestrado em Linguística Aplicada) - Instituto de Estudos da Linguagem, UNICAMP, Campinas, 2005.

McNAMARA, Tim. Language testing: A question of context. In: Challenges, issues, impacts: the interplay of research and language testing practices, caderno de resumos do $27^{\text {th }}$ Annual Language Testing Research Colloquium. Ottawa: University of Ottawa, p. 17, 2005.

Language testing. Oxford: Oxford University Press, 2000.

MOITA LOPES, Luiz Paulo. "Yes, nós temos bananas" ou "Paraíba não é Chicago não", um estudo sobre alienação, e o ensino de inglês como língua estrangeira no Brasil. In: Oficina de Linguística Aplicada. Campinas: Mercado de Letras, 1996, p. 37-61.

Eles não aprendem português quanto mais inglês. A ideologia da falta de aptidão para aprender línguas estrangeiras em alunos de escola pública. In: Oficina de Linguística Aplicada. Campinas: Mercado de Letras, 1996, p. 63-79.

A função da aprendizagem de línguas estrangeiras na escola pública. In: Oficina de Linguística Aplicada. Campinas: Mercado de Letras, 1996, p. 127-189.

PAIVA, Vera Lúcia M. O. (Org). Ensino de Língua Inglesa: reflexões experiências. Campinas: Pontes Editores, 2005.

PINTO, Edevaldo S. Buscando alternativas para o desenvolvimento da competência gramatical de alunos de um curso de Letras de uma faculdade particular. Dissertação (Mestrado em Estudos Linguísticos) 
Douglas A. Consolo; Vera Lúcia Teixeira da Silva

- Instituto de Biociências, Letras e Ciências Exatas, UNESP, São José do Rio Preto, 2004.

QUEVEDO-CAMARGO, Gladys. Avaliar Formando e Formar Avaliando o (Futuro) Professor de Língua Inglesa: uma proposta de construto. Tese (Doutorado em Letras). Londrina: UEL, 2011.

SCARAMUCCI, Matilde V. R. Efeito retroativo da avaliação no ensino/aprendizagem de línguas: o estado da arte. Trabalhos em Linguística Aplicada, v. 43, n. 2, p. 203-226, 2004.

- Proficiência em LE: Considerações terminológicas e conceituais. Trabalhos em Linguística Aplicada, v. 36, p. 11-22, 2000.

SHOHAMY, Elana. The power of tests. Harlow: Longman/Pearson, 2001.

SIMÕES, Giséle Maria. O impacto do estágio nas crenças pedagógicas de professores de inglês em formação. Tese (Doutorado em Estudos Linguísticos) - Instituto de Biociências, Letras e Ciências Exatas, UNESP, São José do Rio Preto, 2011.

TEIXEIRA DA SILVA, Vera Lúcia. Fluência oral: imaginário, construto e realidade num curso de Letras/LE. Tese (Doutorado em Linguística Aplicada) - Instituto de Estudos da Linguagem, UNICAMP, Campinas, 2000.

TELLES, João Antonio (Org.). Teletandem: um contexto virtual, autônomo e colaborativo para aprendizagem de línguas estrangeiras no século XXI. Campinas: Pontes Editores, 2009. 


\section{ANEXO \\ Proposta preliminar de faixas de proficiência \\ para o teste oral do EPPLE}

(Com base em Baffi-Bonvino, 2010; Consolo, 2004; Consolo e

Teixeira da Silva, 2007)

\section{FAIXA A}

A1) Atinge plenamente os objetivos de comunicação verbal, apresentando fluência em velocidade e ritmo de fala.

A2) Exibe padrões de pronúncia bastante semelhante a falantes competentes da língua estrangeira, sem influências marcantes dos padrões de sua língua materna, sem causar qualquer desconforto ou incompreensão por parte do interlocutor.

A3) Fornece informações sobre experiências presentes e passadas de modo claro, e utiliza estruturas linguísticas (por exemplo, formas verbais de passado) e vocabulário, incluindo expressões lexicais ("the year before") adequados e específicos para as necessidades de produção oral.

A4) Narra e descreve, de modo detalhado, uma cena de vídeo. Levanta hipóteses a respeito da cena e estabelece associações com outras experiências, sugerindo contribuições para o ensino e a aprendizagem de língua estrangeira.

A5) Expressa conhecimento sobre regras de uso da língua e seleciona, desse conhecimento, as informações necessárias para esclarecer dúvidas linguísticas de alunos. É capaz de explicar regras linguísticas de modo claro, fazendo uso de terminologia específica, por exemplo, sobre classes de palavras e estruturas gramaticais. As explicações seriam plenamente compreendidas por alunos de língua estrangeira.

A6) Não apresenta dificuldades de compreensão da fala na língua estrangeira em ritmo normal. 


\section{FAIXA B}

B1) Atinge plenamente os objetivos de comunicação verbal, apresentando fluência em termos de ritmo de fala, e se comete erros gramaticais, é capaz de se autocorrigir.

B2) Exibe pronúncia bastante próxima aos padrões de falantes competentes da língua estrangeira, sem influências marcantes dos padrões de sua língua materna, e sem causar incompreensão do interlocutor.

B3) Fornece informações sobre experiências presentes e passadas, e utiliza estruturas linguísticas (por exemplo, formas verbais de passado) e vocabulário, incluindo expressões lexicais ("the year before") adequados e específicos para as necessidades de produção oral.

B4) Descreve uma cena de vídeo. Levanta hipóteses a respeito da cena mas apresenta certa dificuldade em estabelecer associações com outras experiências e para sugerir contribuições para o ensino e a aprendizagem de língua estrangeira.

B5) Expressa conhecimento sobre regras de uso da língua mas apresenta dificuldade em explicá-las de modo claro, ou em selecionar as informações relevantes para esclarecer dúvidas linguísticas de alunos, fazendo uso limitado de terminologia específica de metalinguagem. Suas explicações não seriam plenamente compreendidas por alunos de língua estrangeira.

B6) Não apresenta dificuldades de compreensão da fala na língua estrangeira em ritmo normal.

\section{FAIXA C}

C1) Atinge os objetivos de comunicação verbal, podendo apresentar limitações na fluência, em termos de ritmo e de velocidade de fala, e no uso de estruturas linguísticas.

C2) Exibe pronúncia compreensível, porém com alguns desvios com relação aos padrões de falantes competentes da língua estrangeira. 
C3) Fornece informações sobre experiências presentes e passadas utilizando estruturas linguísticas simples e pouca variedade lexical.

C4) Descreve uma cena de vídeo mas apresenta dificuldade em levantar hipóteses a respeito da cena ou em estabelecer associações com outras experiências, e para sugerir contribuições para o ensino e a aprendizagem de língua estrangeira.

C5) Expressa conhecimento parcial sobre regras de uso da língua mas não consegue explicá-las de modo claro. Tem dificuldade em selecionar informações para esclarecer dúvidas linguísticas de alunos, e sua fala seria compreendida apenas parcialmente por alunos de língua estrangeira.

C6) Pode apresentar dificuldades de compreensão da fala em língua estrangeira mas não a ponto de prejudicarem seu desempenho verbal.

\section{FAIXA D}

D1) Atinge os objetivos de comunicação verbal com limitações. Exibe falta de fluência e de competência no uso de estruturas linguísticas.

D2) Exibe pronúncia compreensível, mas distinta, em alguns aspectos de sons e padrões de entoação, de falantes da língua estrangeira, podendo haver alguma interferência na compreensão e causar certo desconforto ao interlocutor.

D3) Fornece informações sobre experiências presentes e passadas utilizando estruturas linguísticas simples, e pouca variedade lexical.

D4) Descreve uma cena de vídeo mas apresenta dificuldade em levantar hipóteses a respeito da cena e em estabelecer associações com outras experiências, e também para sugerir contribuições ao ensino e à aprendizagem de língua estrangeira.

D5) Expressa conhecimento limitado sobre regras de uso da língua e não consegue selecionar quais informações são relevantes para esclarecer dúvidas linguísticas de alunos, ou não consegue explicar as regras da língua de modo claro. Sua fala seria de difícil compreensão por alunos de língua estrangeira. 
Douglas A. Consolo; Vera Lúcia Teixeira da Silva

D6) Apresenta dificuldades de compreensão da fala na língua estrangeira em ritmo normal, as quais podem, ocasionalmente, prejudicar o desenvolvimento de seu desempenho verbal.

\section{FAIXA E}

E1) Não atinge satisfatoriamente os objetivos de comunicação verbal, apresentando falta de fluência e de competência na produção oral.

E2) Exibe pronúncia nitidamente distinta, em aspectos de sons e padrões de entoação, de falantes da língua estrangeira, com interferências marcantes de sua língua materna, que podem causar incompreensão e desconforto ao interlocutor.

E3) Fornece informações sobre experiências presentes e passadas utilizando estruturas linguísticas simples e pouca variedade lexical, e comete erros estruturais, com prejuízo para sua expressão oral.

E4) Apresenta dificuldade em descrever uma cena de vídeo e em levantar hipóteses a respeito da cena, bem como em estabelecer associações com outras experiências e para sugerir contribuições para o ensino e a aprendizagem de língua estrangeira.

E5) Expressa pouco ou nenhum conhecimento sobre regras de uso da língua, e não consegue explicar regras da língua de modo a esclarecer dúvidas linguísticas de alunos de língua estrangeira.

E6) Apresenta dificuldades de compreensão da fala em língua estrangeira em ritmo normal, as quais prejudicam seu desempenho verbal.

\section{CDAConsolo [EPPLE-2011]}

Submetido em:

Aceito em:

Title: In defense of a language education of quality for foreign language teachers: the EPPLE examination 